\title{
The impact of workplace bullying on flourishing: The moderating role of emotional intelligence
}

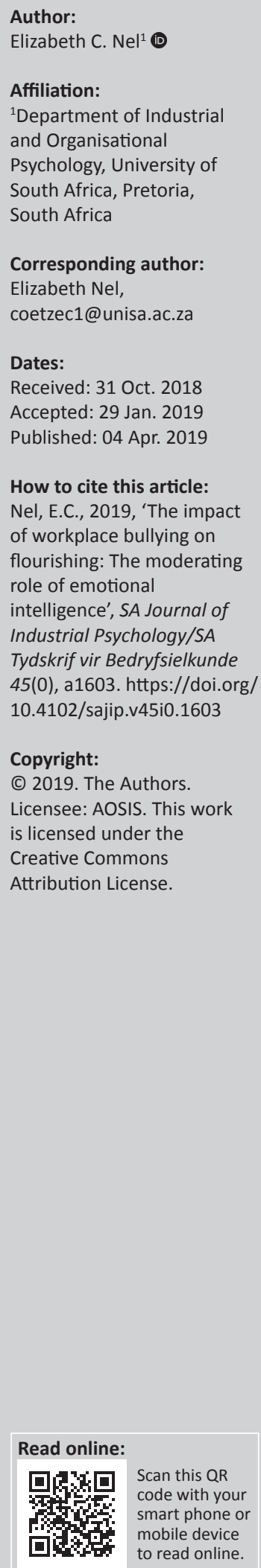

Orientation: Workplace bullying has detrimental effects on employee well-being. Emotional intelligence may moderate the relationship between workplace bullying and flourishing.

Research purpose: The purpose of this study was to examine the nature of the relationship between workplace bullying and flourishing and to investigate the moderating role of emotional intelligence in the workplace bullying-flourishing relationship.

Motivation for the study: There is a paucity of studies exploring the moderating role of personal resources such as emotional intelligence in the relationship between workplace bullying and flourishing.

Research approach/design and method: The study used a cross-sectional design, quantitative approach and a convenience sampling method. Employees from a higher education institution $(N=1102)$ participated in this research. Descriptive, correlation and moderation analysis was used to analyse the data.

Main findings: The results showed that there was a significant negative relationship between workplace bullying and flourishing. Emotional intelligence significantly moderated the relationship between workplace bullying and flourishing.

Practical/managerial implications: Organisations should develop and/or strengthen the level of emotional intelligence in employees in order to reduce the negative effect of workplace bullying on well-being.

Contribution/value-add: The findings of this research contribute to the limited body of research investigating personal resources such as emotional intelligence as a moderator in the bullying-well-being relationship.

Keywords: Industrial and organisational psychology; workplace bullying; well-being; flourishing; emotional intelligence; higher education.

\section{Introduction}

Workplace bullying is an extremely prevalent and relevant issue in modern working life, with devastating effects on employees and organisations (Smit \& Du Plessis, 2016). Exposure to workplace bullying is associated not only with reduced levels of well-being among victims but also with negative individual, group and organisational outcomes (Mathisen, Einarsen, \& Mykletun, 2008). Given the significant costs associated with workplace bullying and the array of negative employee outcomes, it is imperative for organisations to both prevent the onset of bullying and to reduce its negative effects. Despite the wealth of research on the prevalence and antecedents of workplace bullying, little research has been undertaken on understanding the potential moderators in the relationship between bullying and well-being (Nielsen \& Einarsen, 2018; Rai \& Agarwal, 2018). Theoretically, research suggests that the effects of bullying are dependent upon a range of personal resources such as resilience, coping, psychological capital and self-efficacy (Rai \& Agarwal, 2018; Zapf \& Einarsen, 2005). As such, it is proposed that personal resources may reduce the damaging effects of bullying at work on a person's well-being (Bernstein \& Trimm, 2016; Carter \& Loh, 2017; Indoo \& Ajeya, 2012; Upton, 2010). Drawing from the job demands-resources theory (Bakker \& Demerouti, 2007, 2014, 2018), personal resources refer to individuals' personal beliefs regarding the amount of control they have over their work environment (Bakker \& Demerouti, 2007,2014 , 2018). Subsequently, individuals who possess high levels of personal resources have the ability to effectively approach and manage their job demands (Bakker \& Demerouti, 2018), thereby reducing work-related stress and health problems. In terms of the key focus of this study, emotional intelligence was identified as a key personal resource that could act as a protective factor with regard to the negative effects on well-being associated with bullying interactions. 


\section{Research purpose}

The purpose of the study is twofold. Firstly, the study seeks to examine the nature of the relationship between workplace bullying and flourishing. Secondly, the study seeks to investigate whether emotional intelligence significantly moderates the relationship between workplace bullying and flourishing. By conducting this research, the study may potentially contribute to a workplace bullying and well-being theory by shedding light on how personal resources such as emotional intelligence may be helpful in reducing the negative effects of workplace bullying. These findings could further inform employee well-being practices for individuals employed in the diverse South African work environment.

\section{Literature review Workplace bullying}

Workplace bullying is an umbrella term encompassing a range of subtle or obvious negative behaviours, including aggression, hostility, intimidation and harm (Baillien, Neyens, De Witte, \& De Cuyper, 2009; Bartlett \& Bartlett, 2011; Einarsen, Hoel, Zapf, \& Cooper 2011; Escartín, Zapf, Arrieta, \& Rodriquez-Carballeira, 2010; Spagnoli, Spagnoli, Balducci, \& Balducci, 2017; Tehrani, 2012). Einarsen et al. (2011) define workplace bullying as follows:

\begin{abstract}
... harassing, offending, or socially excluding someone or negatively affecting someone's work. In order for the label bullying (or mobbing) to be applied to a particular activity, interaction, or process, the bullying behavior has to occur repeatedly and regularly (e.g. weekly) and over a period of time (e.g. about six months). Bullying is an escalating process in the course of which the person confronted ends up in an inferior position and becomes the target of systematic negative social acts. A conflict cannot be called bullying if the incident is an isolated event or if two parties of approximately equal strength are in conflict. (p. 22)
\end{abstract}

This definition identifies five key elements associated with workplace bullying, which include: (1) negative or aggressive behaviour; (2) the frequency of the behaviour; (3) imbalance of power; (4) harmful effect; and (5) prolonged duration. The first key element, as defined by a number of authors (Baillien et al., 2009; Bartlett \& Bartlett, 2011; Einarsen et al., 2011; Escartín et al., 2010; Spagnoli, Spagnoli, Balducci, \& Balducci, 2017; Tehrani, 2012), can include overt or covert negative behaviours, including harassment, social exclusion, emotional abuse, spreading rumours or physical attacks. Thus, workplace bullying may be person-related (i.e. isolation, social exclusion, false accusations, undermining, harassment, humiliation, threats, intimidation, manipulation, and personal criticism) or work-related (i.e. work overload, removing of responsibility, overruling decisions, controlling resources, unfair criticism and blocking promotion and development opportunities). The second key element emphasises the frequent nature of bullying behaviours. According to Einarsen et al. (2011), Kalamdien (2013) and Leymann (1996), workplace bullying should occur at least once a week because isolated incidents are typically excluded from the defining elements of bullying behaviour (Di Martino, Hoel, \& Cooper, 2003; Einarsen, Hoel, Zapf, \& Cooper 2003; Einarsen et al., 2011). However, several authors indicate that single incidents of extreme hostile behaviour may be classified as bullying if the behaviour causes severe negative consequences for an individual's well-being (Baldry, Farrington, \& Sorrentino, 2017; Lee, 2002; Tehrani, 2012). The third key element describes a power imbalance between the parties, leaving the victim vulnerable (Baillien, Escartín, Gross, \& Zapf, 2017). Remarkably, this imbalance of power between parties is not limited to position or authority (Branch et al., 2013; Cowie, Naylor, Rivers, Smith, \& Pereira, 2002) and can occur downwards, upwards (Branch, Ramsay, \& Barker, 2007, 2008, 2013), horizontally (Einarsen et al., 2011) and across levels (D'Cruz, 2012). The fourth key element highlights the negative physical and psychological effects on victims' health and well-being. On the one hand, psychological problems may include poor mental health, post-traumatic stress, burnout, depression and suicide (Brewer \& Whiteside, 2012; Martin \& Klein, 2013; Nielsen \& Einarsen, 2012; Nielsen et al., 2013; Soares, 2012). On the other hand, physical problems include chronic disease, headaches, higher body mass, increased substance abuse, sleep disruption and an increase in cardiovascular disease (Bartlett \& Bartlett, 2011; Kivimaki et al., 2003). The last key element of workplace bullying underscores the prolonged duration of negative or aggressive behaviour. As such, workplace bullying typically occurs over a long period of time and escalates and intensifies with time (Einarsen et al., 2011; Zapf, Escartín, Einarsen, Hoel, \& Vartia, 2011). To support this view, Einarsen et al. (2011) specify a timeframe of at least 6 months, while Salin (2001) stipulate a duration of at least 12 months within which bullying behaviour should occur.

\section{Flourishing}

Flourishing is commonly used to describe high levels of wellbeing (Diener, Wirtz, Tov, Kim-Prieto, Choi, Oishi, \& BiswasDiener, 2010; Hone, Jarden, Schofield, \& Duncan, 2014; Seligman, 2011). The concept of flourishing was developed by Keyes $(2002,2005,2007)$ and refers to a pattern of positive feelings and positive functioning in life, encompassing emotional, psychological and social aspects of well-being. Flourishing can be linked to several theoretical models that conceptualise flourishing aspects through research conducted by Keyes (2002), Diener et al. (2010), Seligman (2011) and Huppert and So (2013). Keyes (2002) developed the mental health continuum (MHC). The MHC focuses on the way individuals function, both personally and socially, and labels individuals as languishing (i.e. low levels of emotional, psychological and social well-being), moderately mentally healthy (i.e. neither flourishing nor languishing) and flourishing (i.e. high levels of emotional, psychological and social well-being). According to the MHC (Keyes, 2002), flourishing comprises three main components, namely, psychological well-being, social well-being and emotional well-being. Psychological well-being involves aspects of 
an individual's psychological functioning, namely selfacceptance, autonomy, personal growth, positive relations, environmental mastery and purpose in life. Social well-being refers to how an individual functions in a social manner and includes social coherence, social actualisation, social integration, social acceptance and social contribution. Emotional well-being entails the presence of positive emotions, interest in life and satisfaction with life (Keyes, 2002, 2005, 2006). Diener et al. (2010) conceptualised flourishing as the presence of positive relationships, engagement, purpose and meaning, self-acceptance and selfesteem, competence, optimism and social contribution. This model is based on humanistic and positive psychology traditions and includes an individual's psychological and social functioning (Diener et al., 2010). Seligman (2011) conceptualised flourishing in terms of five dimensions: positive emotions, engagement, positive relationships, meaning and accomplishments (the PERMA model). According to Seligman (2011), the PERMA model may assist individuals to find happiness, fulfilment and meaning in their lives. Huppert and So (2013) conceptualised flourishing as the presence of feeling good and functioning effectively. This model highlights mental states rather than physical states and describes flourishing in terms of positive characteristics (i.e. emotional stability, vitality, optimism, resilience and self-esteem); positive functioning (i.e. engagement, competence, meaning and positive relationships); and positive appraisal (i.e. life satisfaction and positive emotion).

\section{Emotional intelligence}

Emotional intelligence was originally developed by Salovey and Mayer (1990) as the appraisal and regulation of emotions and the utilisation thereof to facilitate one's behaviour. Generally defined as an intelligence that involves problemsolving and social relationships (Mayer, Salovey, \& Caruso, 2008), emotional intelligence enables individuals to successfully cope and adapt to workplace stressors (Gunavathy \& Ayswarya, 2012; Van Zyl \& De Bruin, 2012). According to Mayer and Salovey's (1997) four-branch model, emotional intelligence consists of four areas of cognitive abilities: (1) emotional perception; (2) emotional understanding; (3) emotional facilitation; and (4) emotion management. Emotional perception refers to the ability to accurately perceive and express emotions. Emotional understanding involves the use of emotions to facilitate thinking and problem-solving. Emotional facilitation refers to the ability to recognise and analyse complex emotions, while emotion management involves the ability to manage emotions for goal accomplishment (Mayer \& Salovey, 1997). Providing a different perspective of emotional intelligence, the Bar-On (1997, 2000, 2006) model defines emotional intelligence as a range of non-cognitive abilities, social competencies and skills that affect an individual's ability to flourish when faced with daily demands and pressures. The Bar-On $(1997,2000,2006)$ model includes five key components of effective emotional and social functioning: intrapersonal skills; interpersonal skills; stress management; adaptability; and general mood. Intrapersonal skills refer to emotional self-awareness, self-regard, assertiveness and the ability to express one's feelings and be self-directed. Interpersonal skills involve the ability to be aware of, understand and appreciate others' feelings and to establish and maintain mutually satisfying relationships with other people. Stress management refers to the ability to actively and positively cope with stressful situations and the ability to act and control one's emotions. Adaptability involves the ability to remain flexible in changing situations and conditions and to identify and solve personal and social problems. General mood is the ability to maintain a positive attitude towards life, to feel satisfied with one's life and to express positive emotions (Bar-On, 2000). Combining cognitive and personality competencies, Goleman (2001) developed the mixed model of emotional intelligence competencies. According to Goleman (1996), emotional intelligence is not fixed and develops as individuals learn and grow over time. The model is based on the recognition and regulation of emotions in oneself and others, and outlines the following four categories of skills: (1) self-awareness; (2) selfmanagement; (3) social awareness; and (4) relationship management. Self-awareness refers to the ability to recognise emotions in oneself, as well as their impact on decisionmaking. Self-management involves the ability to control one's own emotions and to successfully adjust to changing situations. Social awareness involves the ability to be aware of, understand and react to others' emotions. Relationship management includes the ability to effectively communicate, influence and develop others while building collaboration and managing conflict (Goleman, 2001).

\section{Workplace bullying, flourishing and emotional intelligence}

Numerous studies (Coetzee \& Oosthuizen, 2017; Hansen, Hogh, \& Persson, 2011; Lutgen-Sandvik, Namie, \& Namie, 2009; Nielsen, Magerøy, Gjerstad, \& Einarsen, 2014; Nielsen et al., 2012; Notelaers, 2010) provide support for a relationship between workplace bullying and well-being. More specifically, workplace bullying has been recognised as a major source of workplace stress that is associated with negative well-being outcomes, including poor psychological health, post-traumatic stress, burnout, depression (Brewer \& Whiteside, 2012; Martin \& Klein, 2013; Nielsen et al., 2014; Nielsen, Glaso, Matthiesen, Eid, \& Einarsen, 2013; Verkuil, Atasayi, \& Molendijk, 2015) and even suicide (Bartlett \& Bartlett, 2011). Although a considerable amount of literature is available on the relationship between workplace bullying and various well-being outcomes, limited research efforts have been dedicated towards examining the concept of flourishing as a measure of well-being in relation to workplace bullying. According to the researcher's knowledge, only a single study linking workplace bullying to flourishing has been conducted (Coetzee \& Oosthuizen, 2017).

In terms of emotional intelligence, only a few studies have examined individual personality traits and dispositions as 
moderating variables in the relationship between workplace bullying and well-being. Previous research found that individuals' personal resources such as coping, self-esteem, psychological capital, self-efficacy and resilience moderated the relationship between workplace bullying and various wellbeing outcomes (Ashraf \& Khan, 2014; Bernstein \& Trimm, 2016; Jackson, Firtko \& Edenborough, 2007; Moreno-Jimenez, Rodriguez-Munoz, Moreno, \& Garrosa, 2007; Nielsen \& Einarsen, 2018; Rai \& Agarwal, 2018; Upton, 2010). With specific reference to emotional intelligence, only a small number of studies have suggested a link between workplace bullying and emotional intelligence. These studies suggest that employees high in emotional intelligence are more capable of coping with bullying (Ashraf \& Khan, 2014; Bennett \& Sawatzky, 2013; Cartwright \& Pappas, 2008; Giorgi et al., 2016; Hutchinson \& Hurley, 2013; Oluyinka, 2009). Studies also indicate that individuals high in emotional intelligence tend to experience fewer negative well-being effects resulting from workplace bullying than those with a lower emotional intelligence (EI) (Cartwright \& Pappas, 2008; Slaski \& Cartwright, 2003). This indicates that highly emotionally intelligent individuals appear to be more capable of effectively coping with bullying at work (Raman, Sambasivan, \& Kumar, 2016).

Based on the foregoing discussion, it is evident that workplace bullying causes severe psychological distress (Reknes \& Einarsen, 2018). Personal resources, specifically emotional intelligence, have been found to significantly improve individuals' psychological well-being (Schutte \& Loi, 2014) and their ability to cope with demanding work situations such as bullying (Hutchinson \& Hurley, 2013). Unlike inherent personality traits, emotional intelligence is not fixed and can be enhanced with minimal training (Hutchinson, Hurley, Kozlowski, \& Whitehair, 2018). As such, organisations should consider emotional intelligence training as part of their antibullying strategies.

\section{Conceptual model}

Based on previous research, a conceptual model was developed indicating the hypothesised relationship between workplace bullying and flourishing and the moderating role of emotional intelligence. Workplace bullying is depicted as the dependent variable, while flourishing is the independent variable, whereas emotional intelligence is shown as the moderating variable. The main purpose of this study was to investigate the moderating effect of emotional intelligence on the relationship between workplace bullying and flourishing. The conceptual model, illustrated in Figure 1, indicates the moderating role of emotional intelligence in the relationship between workplace bullying and flourishing.

\section{Statement of hypotheses}

\section{Hypothesis 1}

$\mathbf{H}_{0}$ : Workplace bullying is not significantly and negatively related to flourishing.

$\mathbf{H}_{1}$ : Workplace bullying is significantly and negatively related to flourishing.

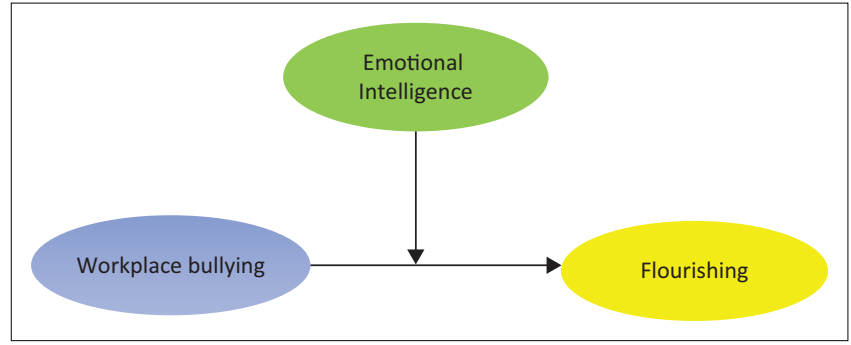

FIGURE 1: Emotional intelligence as a moderator of the relationship between workplace bullying and flourishing.

\section{Hypothesis 2}

$\mathbf{H}_{0}$ : Emotional intelligence is not a significant moderator of the relationship between workplace bullying and flourishing.

$\mathbf{H}_{\mathbf{1}}$ : Emotional intelligence is a significant moderator of the relationship between workplace bullying and flourishing.

The next section of the article will focus on the research design, which comprises the research approach and method, followed by the presentation of the results and a discussion of the findings. The article concludes with a brief summary of the key conclusions, implications for practice and recommendations for potential future research.

\section{Research design Research approach}

A cross-sectional quantitative research approach was followed in order to achieve the research objective.

\section{Research method}

\section{Research participants}

A convenience sample of 1102 employees working within a higher education institution situated in South Africa participated in the study. The participants were colleagues to whom the researcher had access. They were mostly employed at the academic level (65\%) and comprised predominantly $49 \%$ white people and $64 \%$ females in their maintenance career stage $(65 \% \geq 41$ years). The mean age of the participants was 45 years $(\mathrm{SD}=11.31)$. Table 1 presents the profile of the participants.

\section{Measuring instruments}

The Negative Acts Questionnaire - Revised: The Negative Acts Questionnaire - Revised (NAQ-R) developed by Einarsen et al. (2009) is a self-report measurement instrument. The NAQ-R contains 22 items that include three subscales: work-related bullying (7 items; e.g. being ordered to do work below your level of competence), person-related bullying (12 items; e.g. being ignored or excluded) and physically intimidating bullying ( 3 items; e.g. threats of violence or physical abuse or actual abuse). A five-point Likert-type scale was used for subject responses to each of the items. In terms of reliability (internal consistency), Cronbach's alpha coefficients for each subscale range from 0.90 to 0.95 (high) (Carter et al., 2013; Einarsen, Hoel, \& Notelaers, 2009; 
TABLE 1: Sociodemographic characteristics of the participants.

\begin{tabular}{|c|c|c|c|}
\hline Variable & Category & Frequency & Percentage \\
\hline \multirow[t]{5}{*}{ Race } & African & 461 & 42 \\
\hline & Mixed race & 45 & 4 \\
\hline & Indian & 43 & 4 \\
\hline & White & 538 & 49 \\
\hline & Other & 15 & 1 \\
\hline \multirow[t]{3}{*}{ Gender } & Male & 382 & 35 \\
\hline & Female & 705 & 64 \\
\hline & Not indicated & 15 & 1 \\
\hline \multirow[t]{4}{*}{ Age } & 25 years and younger & 22 & 2 \\
\hline & $26-40$ years & 366 & 33 \\
\hline & $41-55$ years & 476 & 43 \\
\hline & 56 years and older & 238 & 22 \\
\hline \multirow[t]{5}{*}{ Qualification level } & Matric certificate & 131 & 12 \\
\hline & Higher certificate & 76 & 7 \\
\hline & Diploma & 118 & 11 \\
\hline & Degree & 158 & 14 \\
\hline & Postgraduate degree & 619 & 56 \\
\hline \multirow[t]{2}{*}{ Job level } & $\begin{array}{l}\text { Administrative } \\
\text { (support staff) }\end{array}$ & 718 & 65 \\
\hline & Academic & 384 & 35 \\
\hline Tenure & $\begin{array}{l}\text { Less than } 5 \text { years } \\
\text { More than } 5 \text { years }\end{array}$ & $\begin{array}{l}436 \\
666\end{array}$ & $\begin{array}{l}40 \\
60\end{array}$ \\
\hline
\end{tabular}

Kakoulakis et al., 2015; Tsuno, Kawakami, Inoue, \& Abe, 2010). In terms of the present study, the overall NAQ-R scale obtained a reliability coefficient of 0.95 . The internal consistency reliability coefficients for the three subscales ranged between 0.79 (physically intimidating bullying) and 0.94 (person-related bullying).

The Flourishing Scale: The Flourishing Scale (FS) developed by Diener et al. (2010) is a self-report measurement instrument. The FS contains eight items relating to positive relationships (e.g. my social relationships are supportive and rewarding), meaning and purpose (e.g. I lead a purposeful and meaningful life), engagement (e.g. I am engaged and interested in my daily activities), social contribution (e.g. I actively contribute to the happiness and well-being of others), competence (e.g. I am competent and capable in the activities that are important to me), self-respect (e.g. I am a good person and live a good life), optimism (e.g. I am optimistic about my future) and social relationships (e.g. people respect me). A seven-point Likert-type scale was used for subject responses to each of the items. In terms of reliability (internal consistency), Diener et al. (2010) established high internal consistency reliability (0.87). In terms of the present study, the overall FS obtained a reliability coefficient of 0.91 .

The Assessing Emotions Scale: The Assessing Emotions Scale (AES) developed by Schutte, Malouff and Bhullar (2009) is a self-report measurement instrument. The AES contains 33 items that include four subscales: perception of emotions (10 items; e.g. I am aware of my emotions as I experience them), managing own emotions (9 items; e.g. I have control over my emotions), managing others' emotions (8 items; e.g. I like to share my emotions with others) and utilisation of emotions (6 items; e.g. when my mood changes, I see new possibilities). A five-point Likert-type scale was used for subject responses to each of the items. In terms of reliability (internal consistency), Cronbach's alpha coefficients for each subscale range from 0.76 to 0.84 (high) (Coetzee \& Schreuder, 2011). In terms of the present study, the overall AES scale obtained a reliability coefficient of 0.91 . The internal consistency reliability coefficients for the four subscales ranged between 0.72 (managing others' emotions) and 0.83 (managing own emotions).

In addition, a biographical questionnaire was used to determine the sociodemographic characteristics (race, gender, age, qualification, job level and tenure) of the participants.

\section{Research procedure and ethical considerations}

A total of 5477 questionnaires were distributed, with 1102 usable questionnaires returned $(N=1102)$, yielding a response rate of $20.12 \%$. The participants were invited to voluntarily participate in the study. The questionnaires were electronically distributed via an e-mail link. Each questionnaire included a cover letter inviting employees to participate in the study and assuring them that their responses would remain anonymous and confidential. The cover letter also stated that completing and returning the questionnaire would be regarded as informed consent and would constitute agreement to use the information for research purposes only.

\section{Statistical analysis}

Statistical analysis was conducted by means of the Statistical Analysis System (SAS) Version 9.4 program (SAS Institute Inc., 2013). Descriptive statistics (means, standard deviations and Cronbach's alpha coefficients), correlation analysis (Pearson product-moment correlation coefficients) and moderation analysis (using Hayes' PROCESS procedure for SPSS version 2.16.3 and Version 3.0 software) were conducted to achieve the objectives of the study. The 0.05 level of significance was selected to determine the presence of significant effects.

\section{Ethical consideration}

Ethical clearance was obtained from the University of South Africa's Ethics Committee (Ref: 2014/CEMS/IOP/017), and permission to conduct the study was obtained from the institution.

\section{Results}

\section{Descriptive statistics and correlations}

The reliability coefficients reported in Table 2 show acceptable internal consistency reliability of the three scales and subscales. The overall reliability coefficient of the NAQ-R was very high $(\alpha=0.95)$ as well as the reliability coefficient for the FS $(\alpha=0.91)$ and AES $(\alpha=0.95)$. These reliability coefficients showed strong overall internal consistency for the three scales. 
TABLE 2: Descriptive statistics: Means, standard deviations, internal consistency reliability coefficients and zero-order correlations $(N=1102)$.

\begin{tabular}{|c|c|c|c|c|c|c|c|c|c|c|c|c|c|}
\hline Number & Variables & Mean (SD) & $\alpha$ & 1 & 2 & 3 & 4 & 5 & 6 & 7 & 8 & 9 & 10 \\
\hline 1 & NAQ-R: Total & $1.64(0.71)$ & 0.95 & - & - & - & - & - & - & - & - & - & - \\
\hline 2 & Work-related bullying & $1.87(0.82)$ & 0.86 & 0.91 & - & - & - & - & - & - & - & - & - \\
\hline 3 & Person-related bullying & $1.56(0.74)$ & 0.94 & 0.97 & 0.80 & - & - & - & - & - & - & - & - \\
\hline 4 & Physically intimidating bullying & $1.40(0.71)$ & 0.79 & 0.84 & 0.64 & 0.82 & - & - & - & - & - & - & - \\
\hline 5 & FS: Total & $6.02(0.89)$ & 0.91 & $-0.19 * * *$ & $-0.20 * * *$ & $-0.17 * * *$ & $-0.11 * * *$ & - & - & - & - & - & - \\
\hline 6 & AES: Total & $3.96(0.47)$ & 0.91 & $-0.07 * * *$ & -0.10 & -0.05 & -0.00 & $0.52 * * *$ & - & - & - & - & - \\
\hline 7 & Perception of emotions & $3.76(0.55)$ & 0.78 & -0.01 & -0.03 & -0.01 & 0.02 & $0.36 * * *$ & 0.85 & - & - & - & - \\
\hline 8 & Managing own emotions & $4.15(0.57)$ & 0.83 & $-0.13 * * *$ & -0.17 & -0.11 & -0.04 & $0.58 * * *$ & 0.90 & 0.62 & - & - & - \\
\hline 9 & Managing others' emotions & $3.95(0.54)$ & 0.72 & -0.05 & -0.06 & -0.04 & -0.00 & $0.46 * * *$ & 0.79 & 0.61 & 0.54 & - & - \\
\hline 10 & Utilisation of emotions & $4.00(0.62)$ & 0.79 & -0.02 & -0.07 & -0.01 & 0.02 & $0.34 * * *$ & 0.80 & 0.54 & 0.49 & 0.51 & - \\
\hline
\end{tabular}

NAQ-R, Negative Acts Questionnaire - Revised; FS, Flourishing Scale; AES, Assessing Emotions Scale.

$*_{* *}^{*}, p \leq 0.001$ - statistically significant; **, $p \leq 0.01$ - statistically significant; $*, p \leq 0.05-$ statistically significant

Hypothesis 1 was analysed by using Pearson's correlation analysis. The results of the analysis are presented in Table 2.

Table 2 shows that all the NAQ-R variables were negatively and significantly associated with the FS $(-0.20 \leq r \leq-0.11$; $p \leq 0.001$; small practical effect). Table 2 further shows that the overall NAQ-R scale significantly and negatively correlated with the overall AES $(r=-0.07 ; p \leq 0.001$; small practical effect) and managing own emotions variable $(r=-0.13 ; p \leq 0.001 ;$ small practical effect $)$.

The overall FS positively and significantly correlated with the overall AES variables $(r=0.52 ; p \leq 0.001$; large practical effect). Furthermore, positive and significant correlations were observed between the FS variable and all four AES variables $(0.34 \geq r \leq 0.58 ; p \leq 0.001$; medium to large practical effect). Overall, the correlation range was below the threshold of $r \leq 0.85$ ) for multicollinearity concerns.

\section{Moderation analysis}

The study proposed that emotional intelligence would moderate the relationship between workplace bullying and flourishing. A statistically significant interaction was found $\left(F p=140.33 ; p=0.001 ; R^{2}=0.28\right)$ for the model of emotional intelligence, workplace bullying and the interaction between workplace bullying and emotional intelligence. The model predicts $28 \%$ of the variance in flourishing. As illustrated in Tables 3-6, the results show that workplace bullying had a significant negative main effect on flourishing $(b=-0.97 ; p<$ 0.001; lower level confidence interval [LLCI] = -1.34; upper level confidence interval [ULCI] $=-0.60$ ). Emotional intelligence also had a significant positive main effect on flourishing ( $b=0.53 ; p<0.001$; LLCI $=0.35$; ULCI $=0.71)$. In addition, workplace bullying was negatively related to flourishing at low $(b=-0.23 ; p<0.001)$ and moderate levels of emotional intelligence $(b=-0.12 ; p<0.001)$ but not at high levels of emotional intelligence $(b=-0.01 ; p=0.79)$. There was a significant interactive effect between workplace bullying and emotional intelligence in predicting flourishing $\left(b=0.21 ; p<0.001 ; \mathrm{LLCI}=0.12 ; \mathrm{ULCI}=0.30 ; f^{2}=0.39-\right.$ large practical effect).

Tables 3-6 further reveal that two levels of the conditional indirect effects of workplace bullying were significantly
TABLE 3: Interactive effect between workplace bullying and emotional intelligence in predicting flourishing (model summary).

\begin{tabular}{lcccccc}
\hline $\boldsymbol{R}$ & $\boldsymbol{R}^{\mathbf{2}}$ & MSE & $\boldsymbol{F}$ & $\boldsymbol{d} \boldsymbol{f} \mathbf{1}$ & $\boldsymbol{d} \boldsymbol{f} \mathbf{2}$ & $\boldsymbol{p}$ \\
\hline 0.53 & 0.28 & 0.64 & 140.33 & 3.00 & 1098.00 & 0.001 \\
\hline
\end{tabular}

$R, R$-value; $R^{2}, R$-squared value; MSE, Mean Square Error; $F, F$-value; $d f 1$, degrees of freedom $1 ; d f 2$, degrees of freedom $2 ; p$, significance.

TABLE 4: Interactive effect between workplace bullying and emotional intelligence in predicting flourishing (model).

\begin{tabular}{lcccccc}
\hline Values & Effect & SE & $\boldsymbol{t}$ & $\boldsymbol{p}$ & LLCI & ULCI \\
\hline Constant & - & - & - & - & - & - \\
EI & 0.53 & 0.09 & 5.70 & 0.001 & 0.35 & 0.71 \\
WB & -0.97 & 0.19 & -5.12 & 0.001 & -1.34 & -0.60 \\
Int_1 & 0.21 & 0.05 & 4.52 & 0.001 & 0.12 & 0.30 \\
\hline
\end{tabular}

SE, Standard Error; $t$, $t$-value; $p$, significance; LLCI, Lower Level Confidence Interval; ULCI, Upper Level Confidence Interval.

TABLE 5: Interactive effect between workplace bullying and emotional intelligence in predicting flourishing $\left(R^{2}\right.$ increase resulting from interaction).

\begin{tabular}{lccccc}
\hline Variable & $\boldsymbol{R}^{\mathbf{2}}$ & $\boldsymbol{F}$ & $\boldsymbol{d f 1}$ & $\boldsymbol{d f \mathbf { 2 }}$ & $\boldsymbol{p}$ \\
\hline Int_1 & 0.01 & 20.45 & 1.000 & 1098.000 & 0.001 \\
\hline
\end{tabular}

$R^{2}, R$-squared value; $F, F$-value; $d f 1$, degrees of freedom $1 ; d f 2$, degrees of freedom 2 ; $p$, significance

TABLE 6: Interactive effect between workplace bullying and emotional intelligence in predicting flourishing (conditional effect of workplace bullying on flourishing at the values of the moderator).

\begin{tabular}{lcccccc}
\hline EI & Effect & SE & $\boldsymbol{t}$ & $\boldsymbol{p}$ & LLCI & ULCI \\
\hline 3.55 & -0.23 & 0.04 & -5.87 & 0.001 & -0.031 & -0.15 \\
4.08 & -0.12 & 0.03 & -3.81 & 0.001 & -0.18 & -0.06 \\
4.60 & -0.01 & 0.04 & -0.27 & 0.790 & -0.09 & 0.07 \\
\hline
\end{tabular}

EI, Emotional intelligence; SE, Standard Error; $t, t$-value; $p$, significance; LLCI, Lower Level Confidence Interval; ULCI, Upper Level Confidence Interval.

negative, as supported by the bias-corrected bootstrap LLCI and ULCI, not including zero in the values range. Tables 3-6 show that when participants experience high levels of workplace bullying and low levels of emotional intelligence, perceptions of flourishing are significantly lower than for those participants with higher levels of emotional intelligence. In contrast, when participants experience low levels of workplace bullying in interaction with emotional intelligence, perceptions of flourishing are significantly higher for both participants with high and low levels of emotional intelligence. The pattern derived from the results diagrammed in Figure 2 confirms the existence of an interactive effect between workplace bullying and emotional intelligence in the prediction of flourishing. 


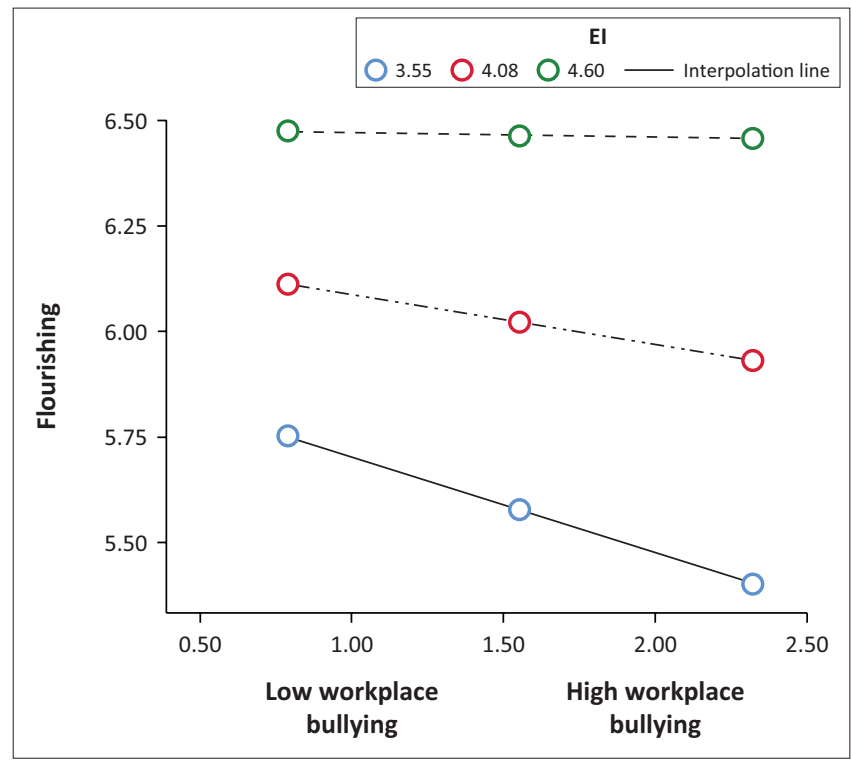

EI, Emotional intelligence.

FIGURE 2: Interactive effect between workplace bullying and emotional intelligence in the prediction of flourishing.

\section{Discussion}

The aim of this study was to investigate whether emotional intelligence moderated the relationship between workplace bullying and flourishing. The results indicated a significant interactive effect been workplace bullying and emotional intelligence in predicting flourishing. Overall, emotional intelligence lowered the effect of workplace bullying in the prediction of flourishing. The findings corroborate previous research that showed a moderating effect of emotional intelligence on the relationship between workplace bullying and employee well-being. More specifically, Raman et al. (2016) argue that highly emotionally intelligent individuals have the capacity to manage the negative experience of workplace bullying more effectively. The findings are also in agreement with previous research studies that suggest that individuals high in emotional intelligence tend to be more capable of coping with bullying at work (Cartwright \& Pappas, 2008). As such, highly intelligent individuals have greater mastery that enables them to manage demanding situations such as workplace bullying more effectively, which in turn prevents them from experiencing negative well-being outcomes (e.g. low levels of flourishing). Thus, emotional intelligence as a personal resource appears to play a significant role in buffering workplace bullying and enhancing the well-being (flourishing) of individuals.

\section{Conclusion}

In conclusion, this research has added to the body of literature on workplace bullying within the South African context by noting that emotional intelligence plays a significant role in moderating the effects of bullying on employees' levels of flourishing. Emotional intelligence includes emotional and social competencies and may thus influence employees' wellbeing by enabling them to cope effectively with bullying situations at work. The development of emotional intelligence is therefore critical to buffer the negative effects of workplace bullying on employees' well-being.

\section{Practical implications}

The current higher education environment places extra demands on employees and involves various workplace stressors, especially workplace bullying. One practical implication of this research is that workplace bullying has a significant impact on employees' well-being. As a result, organisations should develop and implement a workplace bullying policy and ensure a positive and bully-free culture. Organisations should also evaluate whether specific practices and workplace policies accommodate or contribute to workplace bullying, and if necessary, possible modifications to work design and leadership practices should be considered. For example, industrial psychologists could present diversity and awareness training related to workplace bullying, enhance individuals' problem-solving and interpersonal skills in order to manage conflict more effectively, and provide counselling to both the victims and perpetrators of bullying. The second practical implication is the importance of personal resources such as emotional intelligence in reducing the negative effects of workplace bullying on employees' levels of flourishing. In terms of enhancing emotional intelligence, organisations could implement strategies to improve individuals' emotional intelligence through formal or informal training initiatives. More specifically, industrial psychologists could implement emotion-focused training interventions based on Mayer and Salovey's (1997) four-branch model of emotional intelligence. For example, a three-day seminar, based on various work-related emotional intelligence skills (e.g. emotional development, emotional regulation, emotional management and emotional resilience), could be presented. Training and education in emotional intelligence could help reduce the vulnerability of bullying targets and/or assist victims to recover and bounce back from bullying incidents.

\section{Limitations and recommendations}

Although the focus of the study was on the moderating role of emotional intelligence in the bullying-flourishing relationship, it had a number of limitations. Firstly, the sample was obtained from a single higher education institution and can therefore not be generalised to other industries. Prospective studies could collect data from participants employed in other industries to study the generalisability of these findings. Secondly, because of the cross-sectional nature of the research design, this study could make no statements about causality. Future studies could make use of longitudinal studies to overcome this limitation. Thirdly, the possibility of other explanations cannot be ruled out; thus, prospective studies could examine the moderating role of other personal resources, such as psychological capital or coping strategies in the relationship between workplace bullying and well-being. Lastly, future studies using a mixedmethod approach could also be used to gain more in-depth data from interviews. 


\section{Acknowledgements}

Disclaimer: The views expressed in this article are the author's own and not an official position of the institution.

\section{Competing interests}

The author declares that there were no financial or personal relationships that may have inappropriately influenced her in writing this article.

\section{References}

Ashraf, F., \& Khan, M.S. (2014). Does emotional intelligence moderate the relationship between workplace bullying and job performance? Asian Business and Management, 13(2), 171-190. https://doi.org/10.1057/abm.2013.5

Baillien, E., Escartín, J., Gross, C., \& Zapf, D. (2017). Towards a conceptual and empirical differentiation between workplace bullying and interpersonal conflict. European Journal of Work and Organizational Psychology, 26(6), 870-881. https://doi.org/1 $0.1080 / 1359432 X .2017 .1385601$

Baillien, E., Neyens, I., De Witte, H., \& De Cuyper, N. (2009). A qualitative study on the development of workplace bullying: Towards a three-way model. Journal of Community and Applied Social Psychology, 19(1), 1-16. https://doi.org/10.1002/ casp.977

Bakker, A. B., \& Demerouti, E. (2007). The Job Demands-Resources model: State of the art. Journal of Managerial Psychology, 22(3), 309-328. https://doi. org/10.1108/02683940710733115

Bakker, A. B., \& Demerouti, E. (2014). Job demands-resources theory. In C. Cooper $\&$ P. Chen (Eds.), Wellbeing: A complete reference guide (pp. 37-64). Chichester: Wiley-Blackwell.

Bakker, A. B., \& Demerouti, E. (2018). Multiple levels in job demands-resources theory: Implications for employee well-being and performance. In E. Diener S. Oishi, \& L. Tay (Eds.), Handbook of well-being (pp. 1-13). Salt Lake City, UT: DEF.

Baldry, A. C., Farrington, D. P., \& Sorrentino, A. (2017). School bullying and cyberbullying among boys and girls: Roles and overlap. Journal of Aggression, Maltreatment and Trauma, 26(9), 937-951. https://doi.org/10.1080/10926771. 2017.1330793

Bar-On, R. (1997). The Bar-On emotional quotient inventory (EQ-i): A test of emotional intelligence. Toronto: Multi-Health Systems.

Bar-On, R. (2000). Emotional and social intelligence: Insights from the emotional quotient inventory (EQ-i). In R. Bar-On, \& J. D. A. Parker (Eds.), Handbook of emotional intelligence: Theory, development, assessment and application at home, school and in the workplace (pp. 363-388). San Francisco, CA: Jossey-Bass.

Bar-On, R. (2006). The Bar-On model of emotional-social intelligence (ESI). Psicothema, 18, 13-25.

Bartlett, J. E., \& Bartlett, M. E. (2011). Workplace bullying: An integrative literature review. Advances in Developing Human Resources, 13(1), 69-84. https://doi org/10.1177/1523422311410651

Bennett, K., \& Sawatzky, J. V. (2013). Building emotional intelligence: A strategy for emerging nurse leaders to reduce workplace bullying. Nursing Administration Quarterly, 37(2), 144-151. https://doi.org/10.1097/NAQ.0b013e318286de5f

Bernstein, C., \& Trimm, L. (2016). The impact of workplace bullying on individual wellbeing: The moderating role of coping. South African Journal of Human Resource Management, 14(1), 1-12, https://doi.org/10.4102/sajhrm. Resource

Branch, S., Ramsay, S., \& Barker, M. (2007). Managers in the firing line: Contributing factors to workplace bullying by staff - An interview study. Journal of Management and Organization, 13(3), 264-281. https://doi.org/10.1017/S1833367200003734

Branch, S., Ramsay, S., \& Barker, M. (2008). The bullied boss: A conceptual exploration of upwards bullying. In A. Glendon, B. Thompson, \& B. Myors (Eds.) Advances in organisational psychology (pp. 93-112). Bowen Hills: Australian Academic Press.

Branch, S., Ramsay, S., \& Barker, M. (2013). Workplace bullying, mobbing and general harassment: A review. International Journal of Management Review, 15(3) 280-299. https://doi.org/10.1111/j.1468-2370.2012.00339.x

Brewer, G., \& Whiteside, E. (2012). Workplace bullying and stress within the prison service. Journal of Aggression, Conflict and Peace Research, 4(2), 76-85. https:// doi.org/10.1108/17596591211208283

Carter, L., \& Loh, J. (2017). What has emotional intelligence got to do with it: The moderating role of $\mathrm{El}$ on the relationships between workplace incivility and mental health? International Journal of Work Organisation and Emotion, 8(1) 41-58. https://doi.org/10.1504/IJWOE.2017.083791

Carter, M., Thompson, N., Crampton, P., Morrow, G., Burford, B., Gray, C., \& Illing, J. (2013). Workplace bullying in the UK NHS: A questionnaire and interview study on prevalence, impact and barriers to reporting. BMJ Open, 3(6), 1-12. https://doi. org/10.1136/bmjopen-2013-002628

Cartwright, S., \& Pappas, C. (2008). Emotional intelligence, its measurement and implications for the workplace. International Journal of Management Reviews, 10(2), 149-171. https://doi.org/10.1111/j.1468-2370.2007.00220.x
Coetzee, M., \& Oosthuizen, R. M. (2017). Work-role psychosocial flourishing: Its mediation role on workplace bullying and employee turnover intention. Journa of Psychology in Africa, 27(3), 211-215. https://doi.org/10.1080/14330237.201 7.1321826

Coetzee, M., \& Schreuder, D. (2011). The relation between career anchors, emotional intelligence and employability satisfaction among workers in the service industry. Southern African Business Review, 15(3), 76-97.

Cowie, H., Naylor, P., Rivers, I., Smith, P. K., \& Pereira, B. (2002). Measuring workplace bullying. Aggression and Violent Behaviour, 7, 33-51. https://doi.org/10.1016/ S1359-1789(00)00034-3

D'Cruz, P. (2012). Workplace bullying in India. New Delhi: Routledge.

Di Martino, V., Hoel, H., \& Cooper, C. L. (2003). Preventing violence and harassment in the workplace. Dublin: European Foundation for the Improvement of Living and Working Conditions.

Diener, E., Wirtz, D., Tov, W., Kim-Prieto, C., Choi, D., Oishi, S., \& Biswas-Diener, R. (2010). New wellbeing measures: Short scales to assess flourishing and positive and negative feelings. Social Indicators Research, 97, 143-156. https://doi. org/10.1007/s11205-009-9493-y

Einarsen, S., Hoel, H., \& Notelaers, G. (2009). Measuring exposure to bullying and harassment at work: Validity, factor structure and psychometric properties of the negative acts questionnaire-revised. Work and Stress, 23(1), 24-44. https://doi. org/10.1080/02678370902815673

Einarsen, S., Hoel, H., Zapf, D., \& Cooper, C. L. (2003). The concept of bullying at work: The European tradition. In S. Einarsen, H. Hoel, D. Zapf, \& C. L. Cooper (Eds.), Bullying and emotional abuse in the workplace: International perspectives in research and practice (pp. 3-30). London: Taylor \& Francis.

Einarsen, S., Hoel, H., Zapf, D., \& Cooper, C. L. (2011). Bullying and harassment in the workplace: Developments in theory, research, and practice (2nd edn.). Boca Raton, FL: Taylor \& Francis.

Escartin, J., Zapf, D., Arrieta, C., \& Rodriquez-Carballeira, A. (2010). Workers' perception of workplace bullying: A cross-cultural study. European Journal of Work and Organizational Psychology, 20(2), 1-28. https://doi. org/10.1080/13594320903395652

Giorgi, G., Mancuso, S., Fiz Perez, F., Castiello D’Antonio, A., Mucci, N., Cupelli, V., \& Arcangeli, G. (2016). Bullying among nurses and its relationship with burnout and organizational climate. International Journal of Nursing Practice, 22(2), 160-168. https://doi.org/10.1111/ijn.12376

Goleman, D. (2001). An El-based theory of performance. In C. Cherniss \& D. Goleman (Eds.), The emotionally intelligent workplace: How to select for, measure, and improve emotional intelligence in individual, groups, and organizations (pp. 27-44). San Francisco, CA: Jossey-Bass.

Gunavathy, J. S., \& Ayswarya, R. (2012). Emotional intelligence and job satisfaction as correlates of job performance: A study among women employed in the Indian software industry. Paradigm, 15(1-2), 58-65. https://doi. org/10.1177/0971890720110109

Hansen, A. M., Hogh, A., \& Persson, R. (2011). Frequency of bullying at work, physiological response and mental health. Journal of Psychosomatic Research, 70(1), 19-27. https://doi.org/10.1016/j.jpsychores.2010.05.010

Hone, L. C., Jarden, A., Schofield, G. M., \& Duncan, S. (2014). Measuring flourishing: The impact of operational definitions on the prevalence of high levels of wellbeing. International Journal of Wellbeing, 4(1), 62-90.

Huppert, F. A., \& So, T. (2013). Flourishing across Europe: Application of a new conceptual framework for defining well-being. Social Indicators Research, 110(3), 837-861. https://doi.org/10.1007/s11205-011-9966-7

Hutchinson, M., \& Hurley, J. (2013). Exploring leadership capability and emotional intelligence as moderators of workplace bullying. Journal of Nursing Management, 21(3), 553-562. https://doi.org/10.1111/j.1365-2834.2012.01372.x

Hutchinson, M., Hurley, J., Kozlowski, D., \& Whitehair, L. (2018). The utilisation of emotional intelligence capabilities in clinical reasoning and decision making: A qualitative, exploratory study. Journal of Clinical Nursing, 27(3-4), 600-610.

Indoo, S., \& Ajeya, J. (2012). Emotional intelligence and occupational stress among the faculty members of private medical and engineering colleges of Uttar Pradesh: A comparative study. Advances in Management, 5(7), 52-57.

Jackson, D., Firtko, A., \& Edenborough, M. (2007). Personal resilience as a strategy for surviving and thriving in the face of workplace adversity: A literature review. Journal of Advanced Nursing, 60(1), 1-9. https://doi.org/10.1111/j.13652648.2007.04412.x

Kakoulakis, C., Galanakis, M., Bakoula-Tzoumaka, C., Darvyri, P., Chroussos, G., \& Darvyri, C. (2015). Validation of the Negative Acts Questionnaire (NAQ) in a sample of Greek teachers. Psychology, 6, 63-74. https://doi.org/10.4236/ psych.2015.61007

Kalamdien, D. J. (2013). The nature and prevalence of workplace bullying in the Western Cape: A South African study (Unpublished Master's dissertation). University of Stellenbosch, Stellenbosch, South Africa.

Keyes, C. L. M. (2002). The mental health continuum: From languishing to flourishing in life. Journal of Health and Social Behavior, 43(2), 207-222. https://doi. org/10.2307/3090197

Keyes, C. L. M. (2005). Mental illness and/or mental health? Investigating axioms of the complete state model of health. Journal of Consulting and Clinical Psychology, 73(3), 539-548

Keyes, C. L. M. (2007). Promoting and protecting mental health as flourishing: A complementary strategy for improving mental health. American Psychologist, 62(2), 95-108. 
Kivimaki, M., Virtanen, M., Vartia, M., Elovainio, M., Vahtera, J., \& KeltikangasJarvinen, L. (2003). Workplace bullying and the risk of cardiovascular disease and depression. Occupational and Environmental Medicine, 60(10), 779-783. https:// doi.org/10.1136/oem.60.10.779

Lee, D. (2002). Gendered workplace bullying in the restructured UK civil service. Personnel Review, 31(2), 205-227. https://doi.org/10.1108/00483480210416874

Leymann, H. (1996). The content and development of mobbing at work. European Journal of Work and Organizational Psychology, 5(2), 165-184. https://doi. org/10.1080/13594329608414853

Lutgen-Sandvik, P., Namie, G., \& Namie, R. (2009). Workplace bullying: Causes, consequences, and corrections. In P. Lutgen-Sandvik, \& B. D. Sypher (Eds.), Destructive organizational communication (pp. 41-87). New York: Routledge.

Martin, S., \& Klein, A. (2013). The presumption of mutual influence in occurrences of workplace bullying: Time for change. Journal of Aggression, Conflict and Peace Research, 5(3), 147-155. https://doi.org/10.1108/JACPR-03-2013-0008

Mathisen, G. E., Einarsen, S., \& Mykletun, R. (2008). The occurrences and correlates of bullying and harassment in the restaurant sector. Scandinavian Journal of Psychology, 49(1), 59-68. 10.1111/j.1467-9450.2007.00602.x

Mayer, J. D., Salovey, P., \& Caruso, D. R. (2008). Emotional intelligence: New ability or electric traits? American Psychologist, 63(6), 503-517. https://doi. org/10.1037/0003-066X.63.6.503

Moreno-Jimenez, B., Rodriguez-Munoz, A., Moreno, Y., \& Garrosa, E. (2007). The moderating role of assertiveness and social anxiety in workplace bullying: Two empirical studies. Psychology in Spain, 11(1), 85-94.

Nielsen, M. B., \& Einarsen, S. (2018). What we know, what we do not know, and what we should and could have known about workplace bullying: An overview of the literature and agenda for future research. Aggression and Violent Behavior, 42, 71-83. https://doi.org/10.1016/j.avb.2018.06.007

Nielsen, M. B., \& Einarsen, S. (2012). Outcomes of exposure to workplace bullying: A meta-analytic review. Work and Stress, 26(4), 309-332. https://doi.org/10.1080/ 02678373.2012.734709

Nielsen, M. B., Glaso, L., Matthiesen, S. B., Eid, J., \& Einarsen, S. (2013). Bullying and risk-perception as health hazards on oil rigs. Journal of Managerial Psychology, 28(4), 367-383. https://doi.org/10.1108/JMP-12-2012-0395

Nielsen, M. B., Magerøy, N., Gjerstad, J., \& Einarsen, S. (2014). Workplace bullying and subsequent health problems. The Journal for the Norwegian Medical Association, 134(12-13), 1233-1238. https://doi.org/10.4045/tidsskr.13.0880

Notelaers, G. (2010). Workplace bullying: A risk control perspective (Unpublished doctoral thesis). University of Bergen, Bergen, Norway.

Oluyinka, O. A. (2009). Mediatory role of emotional intelligence on the relationship between self-reported misconduct and bullying behaviour among secondary school students. IFE Psychologia, 17(2). https://doi.org/10.4314/ifep.v17i2. 45305

Rai, A., \& Agarwal, U. A. (2018). Workplace bullying and employee silence: A moderated mediation model of psychological contract violation and workplace friendship. Personnel Review, 47(1), 226-256. https://doi.org/10.1108/PR-032017-0071

Raman, P., Sambasivan, M., \& Kumar, N. (2016). Counterproductive work behavior among frontline government employees: Role of personality, emotional intelligence, affectivity, emotional labor, and emotional exhaustion. Journal of Work and Organizational Psychology, 32, 25-37. https://doi.org/10.1016/j. rpto.2015.11.002
Reknes, A., \& Einarsen, H. S. (2018). The role of hardiness in the bullying-mental health relationship. Occupational Medicine, 68(1), 64-66. https://doi.org/10.1093/ occmed/kqx183

Salin, D. (2001). Prevalence and forms of bullying among business professionals: A comparison of two different strategies for measuring bullying. European Journal of Work and Organizational Psychology, 10, 425-441. https://doi. org/10.1080/13594320143000771

Salovey, P., \& Mayer, J. D. (1990). Emotional intelligence. Imagination, Cognition and Personality, 9(3), 185-211. https://doi.org/10.2190/DUGG-P24E-52WK-6CDG

Schutte, N. S., Malouff, J. M., \& Bhullar, N. (2009). The assessing emotions scale. In C. Stough, D. Saklofske, \& J. Parker (Eds.), The assessment of emotional intelligence (pp. 119-135). New York: Springer.

Schutte, N. S., \& Loi, N. (2014). Connections between emotional intelligence and workplace flourishing. Personality and Individual Differences, 66, 134-139. https://doi.org/10.1016/j.paid.2014.03.031

Seligman, M. E. P. (2011). Flourish: A visionary new understanding of happiness and well-being. New York: Free Press.

Slaski, M., \& Cartwright, S. (2003). Emotional intelligence training and its implications for stress, health and performance. Stress and Health, 19(4), 233-239. https:// doi.org/10.1002/smi.979

Smit, D. M. D., \& Plessis, J. V. D. (2016). Why should we care? Bullying in the American and South African workplace. International Journal of Comparative Labour Law and Industrial Relations, 32(2), 161-196.

Soares, A. (2012). When darkness comes: Workplace bullying and suicidal ideation. In N. Tehrani (Ed.), Workplace bullying: Symptoms and solutions (pp. 67-80). Hove: Routledge.

Spagnoli, P., Spagnoli, P., Balducci, C., \& Balducci, C. (2017). Do high workload and job insecurity predict workplace bullying after organizational change? Internationa Journal of Workplace Health Management, 10(1), 2-12. https://doi.org/10.1108/ IJWHM-05-2016-0038

Tehrani, N. (2012). Workplace bullying: Symptoms and solutions. London: Routledge.

Tsuno, K., Kawakami, N., Inoue, A., \& Abe, K. (2010). Measuring workplace bullying: Reliability and validity of the Japanese version of the Negative Acts Questionnaire. Journal of Occupational Health, 52(4), 216-260. https://doi.org/10.1539/joh.L10036

Upton, L. (2010). The impact of workplace bullying on individual and organisational wellbeing in a South African context and the role of coping as a moderator in the bullying-wellbeing relationship (Unpublished Master's dissertation). University of Witwatersrand, Johannesburg, South Africa.

Van Zyl, C. J. J., \& De Bruin, K. (2012). The relationship between mixed model emotional intelligence and personality. South African Journal of Psychology, 42(4), 532-542. https://doi.org/10.1177/008124631204200407

Verkuil, B., Atasayi, S., \& Molendijk, M. L. (2015). Workplace bullying and mental health: A meta-analysis on cross-sectional and longitudinal data. PLoS One, 10(8) 1-16. https://doi.org/10.1371/journal.pone.0135225

Zapf, D., Escartin, J., Einarsen, S., Hoel, H., \& Vartia, M. (2011). Empirical findings on prevalence and risk groups of bullying in the workplace. In S. Einarsen, H. Hoel, D. Zapf, \& C. Cooper (Eds.), Bullying and harassment in the workplace: Developments in theory, research, and practice (pp. 75-106). Boca Raton, FL: CRC Press.

Zapf, D., \& Einarsen, S. (2005). Mobbing at work: Escalated conflicts in organizations. In S. Fox \& P. E. Spector (Eds.), Counterproductive work behaviour: Investigations of actors and targets (pp. 237-237). Washington, DC: American Psychological Association. 